\title{
Research on the Development of Cold Chain Logistics of Agricultural Products
}

\section{E-commerce in Henan Province}

\author{
Huiping $\mathrm{Mu}^{1}$, Shao $\mathrm{Zhou}^{1}$ \\ ${ }^{1}$ school of Management Engineering, Zhengzhou University, No.100 Science Avenue, China \\ 610938227@qq.com
}

Keywords: E-commerce, Cold chain logistics, Agricultural products, China, B2C

\begin{abstract}
With China's economic strength developing and people's living standard improving, people's demand is increasing not only for agricultural products but also for product quality. Henan province is a major agricultural province and it's worthy of the title "China granary", There are large quantities of fresh agricultural products transported to the country and even around the world each year, but due to conventional mode of transportation, higher damage rate of agricultural products exists. According to the data, the province's annual consumption of perishable food is more than 77 million and 400 thousand tons, whose attrition rate in the process of transport can be imagined. In recent years, with the emergence and development of e-commerce industry, a number of electricity supplier enterprises begin to involve fresh agricultural cold chain logistics field, providing convenience for consumers and producers. Based on the actual situation of Henan Province, this paper studies the development of cold chain logistics of agricultural products e-commerce and puts forward the corresponding counter measures.
\end{abstract}

\section{INTRODUCTION}

\subsection{Background of the selected topic}

With the improvement of people's living conditions, simple eating and warm clothes in the past cannot meet the needs of people. Nowadays, consumers' awareness of the safety, freshness and nutritional value of agricultural products has gradually increased. Fresh products are characterized by high water content, easy spoilage and short shelf life, so how to reduce the loss rate of their products during transportation has become one of the important issues to consider. Relevant data show that in Henan, fruits, vegetables and other agricultural by-products of the loss rate of up to $25 \%-40 \%$, while the loss of fruits and vegetables in developed countries can basically be controlled under $5 \%$.

\subsection{Significance of the topic}

B2C is a business to consumer e-commerce model, the development of the Internet makes the consumer attitudes and habits have changed, e-commerce business has been rapid development, especially the B2C business model, make full use of network information platform for online transactions, greatly improve the convenience and effectiveness of fresh agricultural products sales at the same time, to overcome the limitation of space and safety of fresh agricultural products.In recent years, B2C as the representative of the electricity supplier enterprises to fresh agricultural products to invest heavily in operation,as we can see,fresh agricultural cold chain logistics industry will have broad prospects for development.

\section{OVERVIEW OF HENAN E-COMMERCE COLD CHAIN LOGISTICS}

\subsection{The development of cold chain logistics of agricultural products e-commerce in Henan Province}

Henan province is a large agricultural province with a wide range of agricultural products and abundant output. However, due to the poor agricultural equipment and unscientific management, the postpartum loss of the products is serious. In our province, the loss rate of fresh products in logistics links is from $25 \%$ to $30 \%$, and the cost of logistics and transportation can reach $30 \%-40 \%$.It can be said that the technological level of cold chain logistics has a direct impact on the future development of agricultural e-commerce enterprises. With the advent of the Internet era, the sales of goods on the platform in the network more and more domestic enterprises, there has been some large-scale agricultural products processing enterprises of domestic youth base, and even some of the rural cooperative organization opened a network of sales channels. Compared to the traditional sales channels, in the e-commerce model, enterprises and consumers online transactions is convenient and fast. Currently, B2C electronic business platform is divided into agricultural products market related information based integrated service platform and trading oriented electronic business platform, such as Jingdong net fresh SAR and Taobao meow fresh.

\subsection{Characteristics of agricultural products in B2C cold chain logistics}

Cold chain logistics is widely refers to agricultural products in the production of frozen storage, transportation, sales to all aspects of the final consumption is always in low temperature state regulations, to ensure product quality, reduce a technical 
project to avoid postpartum loss. For agricultural products in fruits and vegetables, meat, aquatic products such as perishable, short shelf life of fresh products, must be implemented throughout the cold chain. The implementation and management of cold chain logistics of agricultural products under the electronic commerce has the characteristics different from other products:

\subsubsection{Strong timeliness}

Supplier by sales of agricultural products are mostly short shelf life, easy to decay, with strong seasonal products. So far, most of the electricity supplier in the agricultural sales competition is not just price, but the temperature, speed and freshness competition. Therefore, the timeliness of e-commerce of agricultural products is an important competitive means for the major electricity suppliers to improve product quality and reduce consumption.

\subsubsection{Scattered volume}

The development time of e-commerce for fresh agricultural products is not long, and for the growth phase, most of the consumer spending habits still stay in the physical store to buy. All the ideas of consuming fresh agricultural products on the Internet are not fully formed, therefore, most of the orders on the Internet show a small quantity of orders and scattered characteristics. At the same time, it brings difficulties to the transportation of agricultural products, e-commerce and cold chain logistics. The scattered distribution is not conducive to the formation of large-scale effects, while increasing costs.

\subsubsection{High cost}

The transport of cold chain logistics of fresh agricultural products with big difference with our traditional products logistics, cold chain logistics of agricultural products in the production, transportation, need throughout the cold chain control, temperature on the sale of the entire process, humidity strict requirement, involving multiple links and logistics refrigerator, refrigerator, refrigerator etc. a variety of equipment, professional personnel also need to monitor the whole process instruction distribution. Therefore, businesses need to assume huge investment and operational risks, and transport costs are accounted for $25 \%-40 \%$ of the total cost of products.

\section{PROBLEMS AND CHARACTERISTICS OF COLD CHAIN LOGISTICS IN HENAN E-COMMERCE}

\subsection{Lack of continuity}

Cold chain logistics focus is not in fact the word "cold", but in a "chain", it must form a complete chain, from production, circulation, to the final consumer, interlocking on the middle and lower reaches of, only one side of the work is not enough. At present, Henan Province enterprises, government and trade associations lack communication and cooperation, and there is no overall planning integration, so the current e-commerce, agricultural products and cold chain logistics market is relatively confusing. In addition, the agricultural electricity supplier website cold chain logistics coverage area is uneven, mostly concentrated in a higher level of consumption of the city, or the origin of agricultural products area, and the remaining two or three line cities are rarely covered

There is no communication between the upper, middle and lower reaches of cold chain logistics of fresh agricultural products in Henan Province, and the information cannot be shared. The producers of agricultural products in the upper reaches are mostly retail investors, and there is a lack of organizational communication between them. Therefore, the cold chain logistics in rural areas is basically blank. Because of the upper's unstable situation, the supermarkets, which is in the middle of the cold chain, focus on the product sales and frozen processing sectors instead of the quality of the products. There is no communication between each link, the information is not smooth, over time, it will become a bottleneck in the development of cold chain logistics industry.

\subsection{Postponement of information technology}

The development level of cold chain logistics of e-commerce and agricultural products in Henan province is relatively backward. The first is the lack of high-tech equipment in cold chain logistics. The data show that in 2005, China's Refrigerated thermal insulation car is only about 34000, only the same period the United States refrigerated insulation car $1 / 7$, Japan's $1 / 4$. We have refrigerated control cars accounted for only $0.3 \%$ of all freight cars, however, the United States is $1 \%, 2.6 \%$ in the United Kingdom, Germany and even up to 3\%.In addition, the lag of information system of fresh agricultural products cold chain logistics of our leading cold chain logistics managers have to grasp the relevant information on the latest, almost without a unified information system planning set, only have to provide a function of the software, the level of the cold chain logistics enterprise is also uneven. Secondly, cold chain logistics of fresh agricultural products has not been popularized in the whole province.

\subsection{The low proportion of third party cold chain logistics}

With the development of e-commerce platform, consumers online shopping more and more widely, from the beginning of the brand clothing, digital products, food to the fresh agricultural products, which stimulated the high-end agricultural products demand at the same time, also stimulated the development of cold chain logistics of agricultural products. But in Henan, except for agricultural products that are used for large foreign trade exports, most of the logistics and transportation of fresh products are carried out by farmers themselves or farmers' markets or electricity suppliers themselves, the proportion of third party cold chain logistics is not high. In Henan, "cold King refrigerated Logistics Transportation Co., Ltd.", is the only one with basic facilities of the third party cold chain logistics, and its service object only involves Shuanghui, Sinian, Mengniu and some other leading enterprises in Henan Province. 
In addition, this is one of the few third party cold chain logistics infrastructure, which information systems, professional technology, service quality cannot fully meet the requirements of agricultural products, electricity suppliers and consumers. In our province and even the whole country, the degree of socialization of cold chain logistics and the gap between the technical level and developed countries are still very big, which has become the joint point of restricting the development of e-commerce of fresh agricultural products. Based on the concerns about the quality of the cold chain transportation and the quality of fresh agricultural products, consumers tend to wait and see when they buy. Now, the third party cold chain logistics technology is not fully mature, and there is a certain degree of risk and high outsourcing costs. These factors have led to electricity supplier enterprises prefer to undertake their own distribution business and develop relevant warehousing and transportation departments. For example, SF with its perfect logistics system, in 2014 launched a comprehensive cold chain logistics business, terminal service station initiated by Jingdong, preparing to try to arrive directly from the field in the future, which is ABC”(Agricultural to Business to Customer)method. In this way, on the one hand, leading enterprises rarely outsource cold chain logistics of third parties, On the one hand, the demand gap of agricultural products to the third party cold chain is larger, which leads to the suspicion that the cold chain logistics has the tendency of abnormal development. However, whether it is self built electricity supplier or third party cold chain logistics are in the trying stage, there is no mature cold chain logistics system. In a word, the socialization degree of cold chain logistics of our agricultural products is still relatively low, and it requires the third party logistics enterprises to accelerate the development and popularization.

\subsection{Unsound system of laws and regulations}

There are many kinds of agricultural products which need cold chain logistics transportation, different kinds of agricultural products may not meet the requirements of temperature, humidity and type of space. The cold chain logistics of agricultural products in Henan is still in its initial stage of development, and there is no uniform standard for the industry, and the government's overall supervision of the industry is not enough. Therefore, now just rely on some standards formulated by the enterprise itself, and rely on the conscious implementation of the enterprise. The complex system standards involved in cold chain, such as transport temperature standards, refrigeration configuration requirements for refrigerated vehicles, temperature control systems, and specifications for information management systems, are not documented.

\section{RESEARCH ON THE DEVELOPMENT OF HENAN ELECTRICITY SUPPLIER AGRICULTURAL COLD CHAIN LOGISTICS}

\subsection{Build up the facility of technology}

Improve the electronic commerce of cold chain logistics development level, the first is to strengthen the level of information technology, to achieve the information sharing between the cold chain logistics enterprises, the relevant government supervision departments as the Internet information system behind the third parties, monitoring the operation of the entire market and big data analysis.

\subsection{Element various forms of system of alliance}

Guide retail investors to actively participate in rural cooperatives, and then through cooperative organizations and small and medium-sized cold chain logistics enterprises to form a cooperative alliance, The origin of the wholesale market can cooperate with large third party logistics enterprises, combined with some common downstream wholesale market formed a strategic partnership. Similarly, downstream of the wholesale market through a combination of small and medium-sized logistics enterprises, large chain supermarkets, convenience stores and other communities. Thus, the whole chain is linked together to form a complete supply chain, and the cost sharing is realized through cooperation among them, which reduces the risk of cold chain disruption.

\subsection{The initial investment of government and the implementation of preferential policies}

The establishment of cold chain logistics system of fresh agricultural products is not only pure commercial behavior, but also has certain social significance, Therefore, it is necessary for the government to guide and support in the early stage, at the same time implement preferential policies to help the industry stand firm, and then gradually realize the government and the market's common regulatory role. In view of the characteristics of large investment, high cost, strict technical requirements and difficult supervision, the cold chain logistics industry of agricultural products has these characteristics, As a big agricultural province, it is necessary to increase the intensity of policy support for the development of cold chain logistics of agricultural products in Henan. First of all, we can support the financing of cold chain logistics enterprises of agricultural products, carry out financial subsidies, and expand the scope of preferential tax policies, This can reduce the burden on enterprises to a certain extent, to provide interest free loans or increase the repayment time, allow foreign investment to create a loose environment for the marketing of agricultural products cold chain logistics business enterprise. Secondly, we can consider simplifying the examination and approval process during the establishment of enterprise registration, reducing the barriers to entry, and even setting up special funds to help the construction of cold chain logistics of agricultural products. At the same time, the government and other relevant departments need to establish a perfect cold chain logistics monitoring system and information platform for fresh agricultural products.

\subsection{Train qualified people to meet the needs of the country}

Cold chain logistics of agricultural products e-commerce in Henan has just started, but it has broad 
prospects for development. In order to develop this new industry as soon as possible, machinery, equipment and the government's capital investment are indispensable, and it is essential for the training of talents in the industry. In rural areas, large local rural cooperative organizations carry out propaganda on basic e-commerce technology and e-commerce marketing knowledge; Secondly, we should encourage all colleges and universities to carry out corresponding subjects; After that, we should strengthen the professional training of the middle and senior technical personnel and important management personnel of the e-commerce enterprises, cold chain logistics enterprises, and improve their professional quality and technical ability.

\section{CONCLUSIONS}

Although in the agricultural industry, the electronic commerce of the cold chain logistics development is still in its infancy, but believe in the government's international support and catalytic power, consumers of the cold chain logistics acceptance will gradually increase, the domestic e-commerce cold chain logistics enterprises will quickly rise.

\section{REFERENCES}

[1] Kai, Fang.D,2013, Research on the development of cold chain logistics of agricultural products. Huazhong Agricultural University.

[2] Zhigang, Wang, Qikui, Wang, J, 2012.Developing status of agricultural products cold chain logistics industry, problems and Countermeasures of the prospect of Agricultural Outlook.

[3] Rui, Yang, D, 2015. Optimization of cold chain logistics of agricultural products in China based on Internet of things. Shanxi University of Finance and Economics.

[4] Rong, Luo. D, 2014.Research on performance evaluation of cold chain logistics of fresh agricultural products under the background of e-commerce. Huazhong Agricultural University, [5] Qiuyan, Ma. D, 2015.Henan province fresh agricultural products cold chain logistics development studies. Zhengzhou University.

[6] Lina, Chang, D, 2015. Study on standardization system of cold chain logistics of agricultural products under logistics management. Qufu Normal University.

[7] Yulan, Hong, Qirong, Xiao, J, 2015. Problems and development suggestions of cold chain logistics of agricultural products in China. logistics science and technology.

[8] Li, Xuefeng, Wang, Ying, Chen, Xi, J, 2012.Cold chain logistics system based on cloud computing. Concurrency Computat.: Pract. Exper.

[9] An, Jiuyi,J,2015. Research on Agri-Food Cold Chain Logistics Management System: Connotation, Structure and Operational Mechanism. Journal of Service Science and Management. 